\title{
Epidemiological analysis of pediatric patients with thoracoabdominal trauma in the emergency department
}

\author{
Cengiz Güiney ${ }^{1}$, Abuzer Coskun²
}

${ }^{1}$ Sivas Cumhuriyet University Medical Faculty, Department of Pediatric Surgery, Sivas, Turkey

${ }^{2}$ Sivas Numune Hospital, Department of Emergency, Sivas, Turkey

Corresponding author: Abuzer Coskun, MD, Sivas Numune Hospital, Department of Emergency, Sivas, Turkey

E-mail: dr.acoskun44@ hotmail.com

Received/Accepted: May 24, 2019 /June 25, 2019

Conflict of interest: There is not a conflict of interest.

\section{SUMMARY}

Objective: The study aimed to evaluate the causes of trauma, diagnostic treatment methods, and the results in the patients who were admitted to the emergency department with pediatric thoracic and abdominal trauma.

Method: In this study, between January 2014 and December 2018, 959 patients under 18 years of age who were admitted to the emergency department due to the thorax and abdominal trauma were included. Of these, $557(58.1 \%)$ were male, with a mean age of 9.3 years (range, 1-16 years). Demographic characteristics, trauma patterns, and mortality results of these patients were evaluated retrospectively.

Results: 933 (97.3\%) of the cases were blunt, and 2 (2.7\%) were penetrating traumas. Of the trauma cases, $436(4.5 \%)$ fell from lower than one meter, 323 $(33.7 \%)$ fell from higher than one meter, $174(18.1 \%)$ were in or nonvehicle traffic accidents, $26(2.7 \%)$ were penetrating or sharp object injuries. Mortality was most common in men. Also, mortality was observed in 11 $(1.14 \%)$ cases with a fall from height and then $4(0.4 \%)$ cases in a nonvehicle traffic accident. Abdominal organ injury was mostly in the liver, but mortality was more frequent in spleen injuries. Thoracal, lumbar and simple rib fractures were detected mostly in falls, and hemo and pneumothorax were detected in non-vehicle traffic accidents.

Conclusions: Most of the thoracic and abdominal traumas can be treated by conservative methods. Mortality and morbidity rates can be decreased by determining the multidisciplinary approach of other system injuries and by giving the early decision of procedures.

Keywords: Emergency, pediatric thoracic and abdominal traumas, intraabdominal organ injuries, mortality

\section{Cengiz Güney}

Abuzer Coşkun

ORCID IDs of the authors: C.G. $0000-0001-9052-741 \mathrm{X}$ A.C. $0000-0003-4824-7021$ 


\section{INTRODUCTION}

In the trauma child age group; It is the most important cause of morbidity and mortality in developing and undeveloped countries 1. Anatomical structures and physiology of children are different from adults. Also, their environment and interests vary from age to age. Although the mechanisms and types of accidents in children vary, the most common causes of trauma in children are car accidents, falls, bike accidents, drowning, burns, and child abuse ${ }^{2}$. Traumas that may be so fatal in childhood and which may cause sequelae should be evaluated in terms of causes, age distribution, and treatment algorithms.

The epidemiology of traumas in the region should be well known to establish a viable and life-saving algorithm and determine requirements until the patient is delivered to the hospital. Pediatric patients who were admitted with trauma were followed up and treated by outpatient or inpatient care were examined. Trauma types, injuries, and results are discussed in the light of literature.

\section{MATERIAL AND METHODS}

A total of 959 pediatric patients with thoracic and abdominal trauma who were brought to the emergency departments of Sivas Cumhuriyet University Health Services Application and Research Hospital and Sivas Numune Hospital between January 2014 and December 2018, who were followed up or hospitalized, were included in the study.

The study included patients with falls from height, traffic accidents, and sharp object injuries. Gunshot wounds were not included in the study. Patients falling from heights were divided into two groups as falling from heights below 1 meter $(-1 \mathrm{mF})$ and falling from heights above 1 meter $(+1 \mathrm{mD})$. Traffic accidents were classified into two groups as vehicle traffic accidents and non-vehicle traffic accidents. Organ injuries were determined by imaging methods (ultrasonography, computed tomography, direct radiography). The patients were retrospectively evaluated for age, gender, causes of trauma, pathologies related to trauma, and mortality reasons.

This study was conducted with the approval of the Sivas Cumhuriyet University Clinical Research Ethics Committee.

\section{Statistical Analysis}

The data obtained from this study were analyzed using SPSS 20 package program. While investigating variables from a normal distribution, Shapiro Wilk's was used due to the number of units. Descriptive statistics were shown as mean \pm standard deviation or median (minimummaximum) for continuous variables, and nominal variables were shown as several cases and percentage (\%). Chi-square analysis was applied to examine the relationship between nominal variables among the groups. If the predicted values in the cells of $2 \times 2$ tables were not high enough, Fisher's exact test was used, and the Pearson Chi-square test was used with the help of Monte Carlo Simulation to analyze $\mathrm{RxC}$ tables. While evaluating the results, 0.05 was used as the level of significance and values below $\mathrm{p}<0.05$ were considered statistically significant.

\section{RESULTS}

The mean age of the patients was $9.3 \pm 3.1$, and the male / female ratio was $1.38 .58 .1 \%$ (557) of the patients were male, and $48.1 \%$ (402) were female patients (Table 1). The number of male patients was significantly higher $(\mathrm{p}<0.001)$. There was no significant difference in trauma types by age. The mean age of the vehicle accident group and the penetrating injuries group was relatively higher (Fig 1). 
Table 1: Baseline characteristics of study patients.

\begin{tabular}{|c|c|c|c|c|c|c|c|}
\hline \multicolumn{8}{|c|}{ Study Patients } \\
\hline \multicolumn{5}{|c|}{$\begin{array}{l}\text { Basaline Characteristcis } \\
\text { value }\end{array}$} & \multicolumn{3}{|c|}{ All patients } \\
\hline \multicolumn{5}{|c|}{ Age, mean \pm SD, yr } & $9.3 \pm 3.1$ & $\mathrm{Z}=-1.125$ & 0.261 \\
\hline \multicolumn{5}{|c|}{ Sex, Female/Male } & $402 / 557$ & $X^{2}=92.637$ & 0.001 \\
\hline \multirow{2}{*}{\multicolumn{4}{|c|}{ Mortality }} & No & Yes & & \\
\hline & & & & $9.3 \pm 3.0$ & $9.2 \pm 2.8$ & $\mathrm{Z}=0.281$ & 0.779 \\
\hline \multirow{2}{*}{$\begin{array}{l}\text { Trauma } \\
\text { Types }\end{array}$} & $-1 \mathrm{mF}$ & $+1 \mathrm{mD}$ & ICTA & NCTA & PCTI & & \\
\hline & $9.3 \pm 2.9$ & $9.3 \pm 3.0$ & $9.7 \pm 3.5$ & $9.1 \pm 3.1$ & $9.9 \pm 3.5$ & $\mathrm{H}=2.123$ & 0.713 \\
\hline
\end{tabular}

-1mF: Falls up to one meter, +1mD: Drops from a meter and more, ICTA: In-car traffic accident, NCTA: Non-vehicle traffic accident, PCTI: Penetrating-cutting tool injury, FR; Fluid Resuscitation $\quad p<0.05$

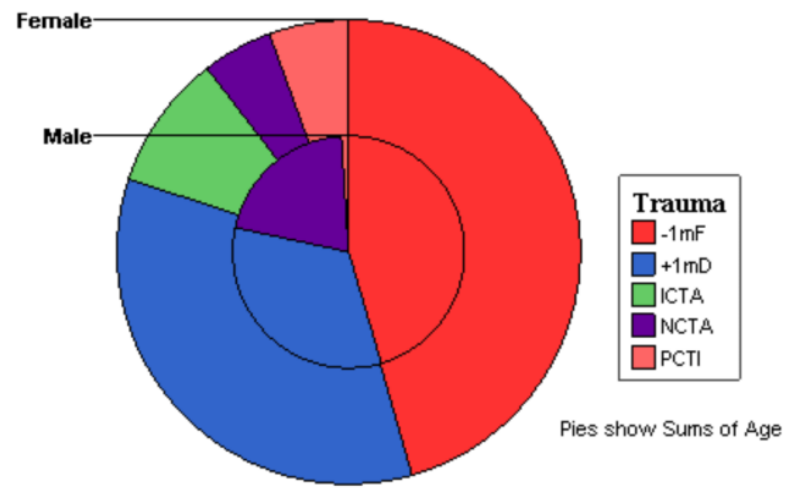

Figure 1: Age distribution of trauma types by gender

Significant differences were found in chi-square test according to whether the types of trauma were determined according to the localization of the thoracic injury (right, left, bilateral), according to the sex, according to the types of rib fractures (single, 2-3, flail chest, sternum injury), according to the presence of hemothorax (Hx) and/or pneumothorax $(\mathrm{Px})$, according to the types of organ injury (liver, spleen, other) According to the results of the study, significant differences were found in the chi-square test (Table 2, Fig. 2).

There was a statistically significant difference in types of injury according to gender. In the vehicle accident group, there were no male patients, whereas the number of female patients was higher in the penetrating injuries group. The bilateral thoracic injury was more frequent in the $+1 \mathrm{mD}$ group in terms of thoracic injury type and left thoracic injury was more common in the vehicle accident group. The incidence of right hemithorax injuries was higher in the injuries due to nonvehicle traffic accidents. Unilateral (right + left) thoracic injuries were more frequent in $+1 \mathrm{mD}$. Lung contusion was most common in the $+1 \mathrm{mD}$ group.

It was determined that single-rib fracture was the most common pathology in all trauma types. Sternum fracture was less common in vehicle accidents and penetrating injuries groups. Injury causing flail chest was found to be less in the $1 \mathrm{mF}$ and penetrating injuries group.

Px was most frequently seen in the vehicle accident group, but in the $-1 \mathrm{mF}$ group Px was not seen. Hx was the most common in the nonvehicle accident group, but it was not found in the vehicle accident group. Injuries leading to intraabdominal bleeding were more common in the $+1 \mathrm{mD}$ and non-vehicle accident group.

Liver injuries were significantly higher in the $+1 \mathrm{mD}$ group, and splenic trauma was more frequent in the non-vehicle accident group. Other organ injuries (intestine, mesentery, pancreas, etc.) were equally distributed according to trauma types. 
Table 2: Chi-square test of trauma types with variables

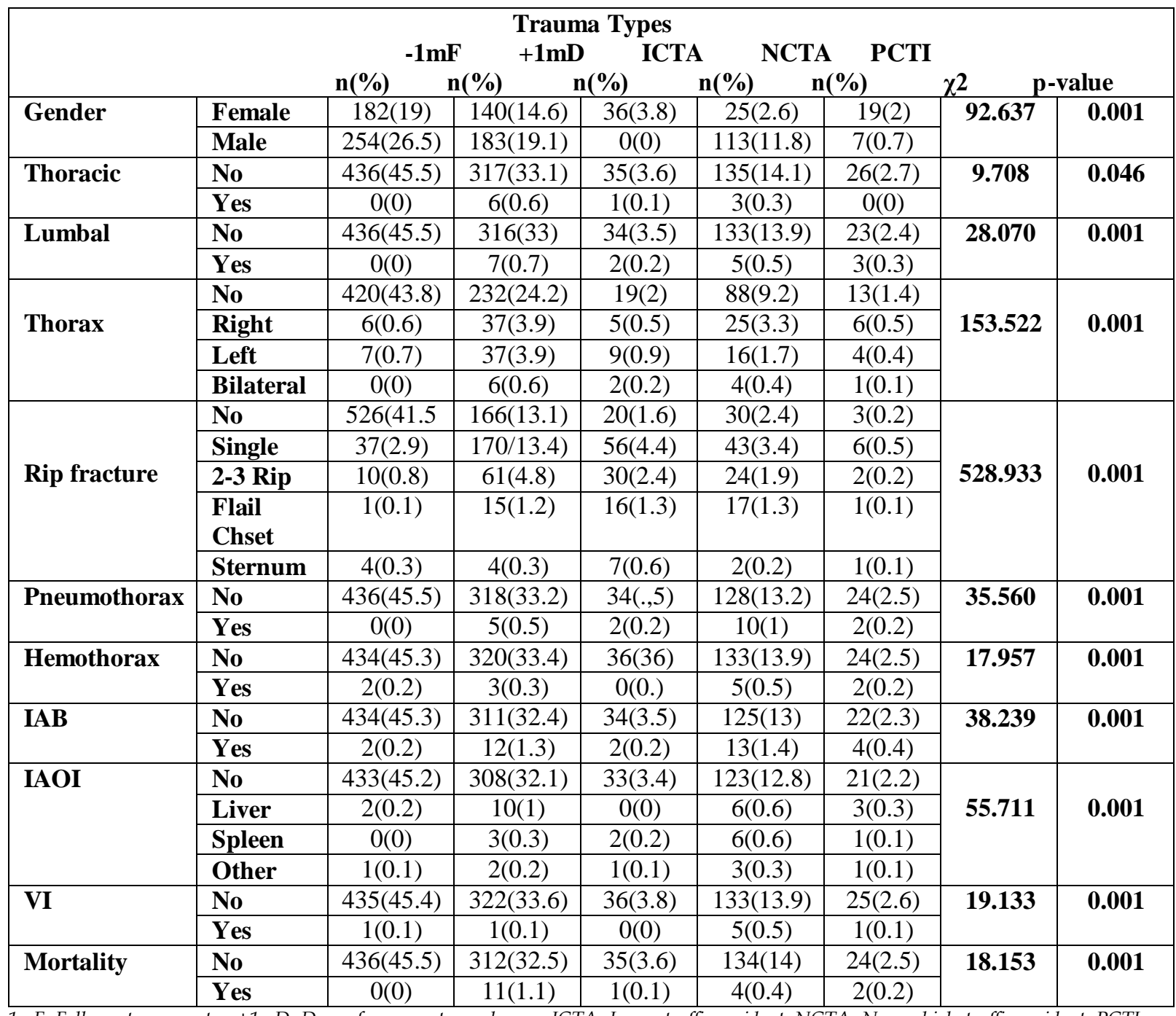

-1mF: Falls up to one meter, $+1 \mathrm{mD}$ : Drops from a meter and more, ICTA: In-car traffic accident, NCTA: Non-vehicle traffic accident, PCTI: Penetrating-cutting tool injury, FI; Firearm injury, FR; Fluid Resuscitation, IAB: Intraabdominal Bleeding, IAOI: Intra-abdominal organ injury, VI: Vessel injury

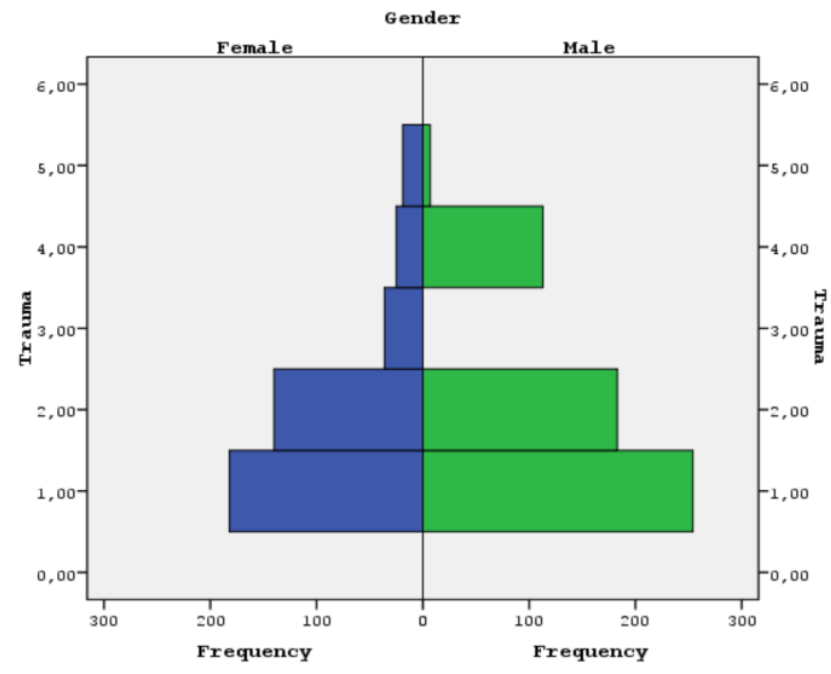

Figure 2: Gender distribution of trauma types 
Table 3: Chi-square test of variables with mortality

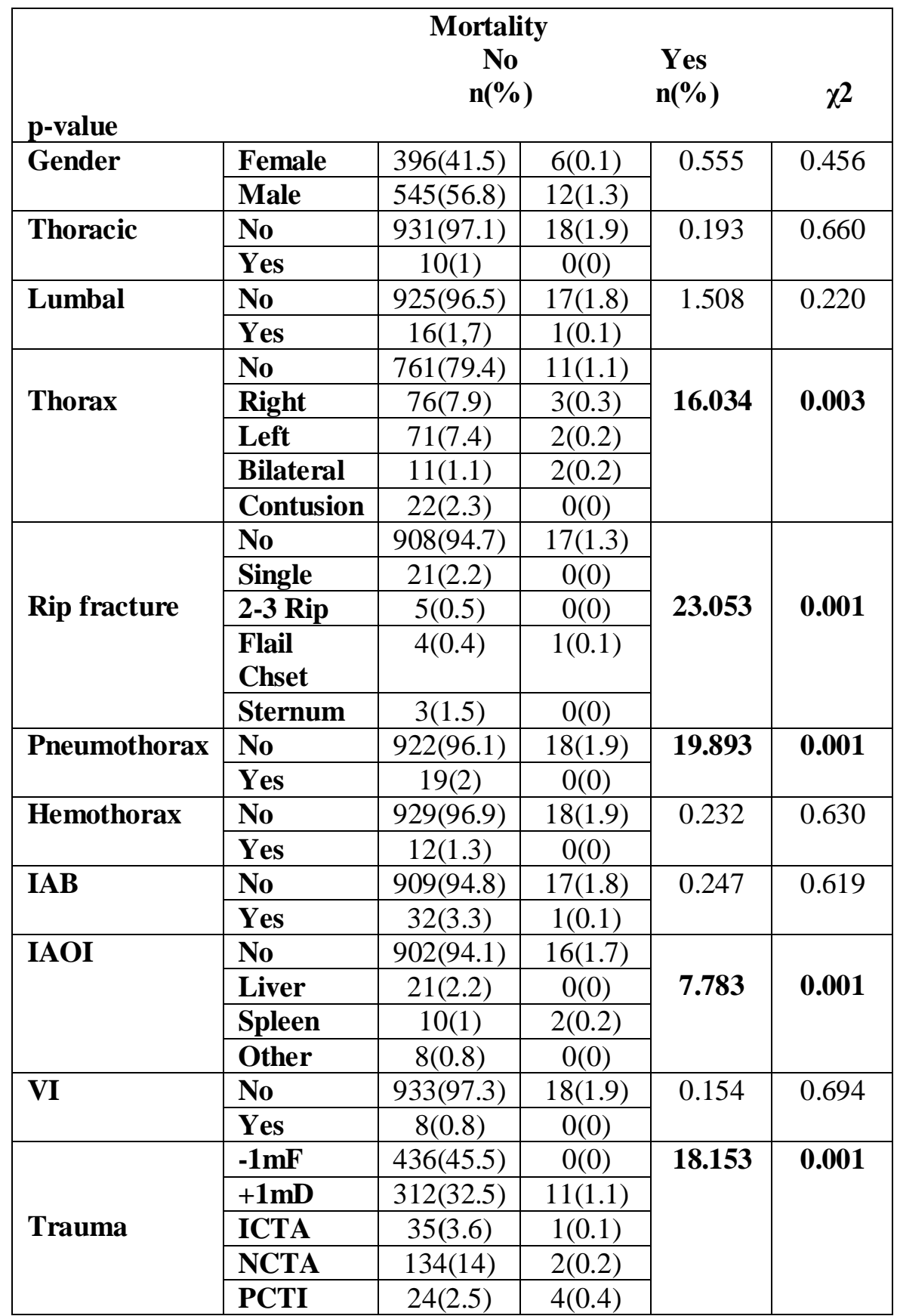

Significant differences were found in the statistical analysis of mortality about thoracic injury localization, rib fracture types, presence of Px, types of organ injury (Table 3 ). Not having; thoracic injuries, rib fractures, Px, organ injuries were found to be statistically significant in injuries that did not result in mortality. When the relationship between mortality and trauma types was examined, it was determined that the most common type of trauma that causes mortality was $+1 \mathrm{mD}$, and there was no mortality in the $-1 \mathrm{mF}$ group and it was found to be statistically significant. There was no statistically significant relationship between sex, intra-abdominal hemorrhage, and presence of $\mathrm{Hx}$ and mortality.

\section{DISCUSSION}

In our country, as well as in the world, trauma, which is the most common cause of mortality and morbidity in the pediatric age group, is one of the most important health problems ${ }^{1}$. Our study included the evaluation of trauma types and 
trauma-induced pathologies of patients in the pediatric age group brought to the emergency department of two health centers and their relationship to mortality.

The causes of traumas, which can cause fatal and permanent disabilities and the fact that they constitute a wide scale ranging from infancy to adulthood in terms of age, have difficulties in terms of creating an algorithm. Anatomical and physiological differences cause trauma to cause different pathologies in children. Factors such as climate, culture, development, season, time of day, and age are effective in the frequency of trauma of children ${ }^{3}$.

Studies have shown that boys are exposed to more trauma ${ }^{4-6}$. In our study, trauma was more common in boys, and the most common cause of trauma was $-1 \mathrm{mF}(45.5 \%)$. In females, the most common cause of trauma was $-1 \mathrm{mF}(45.3 \%)$.

One of the most important groups of patients who applied to the emergency department due to trauma is traffic accidents. The rate of traffic accidents has been reported as 46-59\% 7,8. However, in our study, it was found that the rate of children brought by traffic accident was $18.1 \%$. In this respect, our study does not show any parallelism with current literature data. This situation was evaluated as a result of the high number of patients in $-1 \mathrm{mF}$ group in our study and the centers where we conducted the study were easily reached and centralized in terms of transportation.

Since thoracic injuries are a reliable predictor of the severity of injury in children, it is essential to carefully assess children with thoracic trauma. If these injuries are not detected and properly approached, the morbidity risk of children becomes $50 \%$ or higher ${ }^{9}$. Pulmonary contusion described by Morgagni in 1971 is a common type of injury due to thoracic trauma. Pulmonary contusion is detected in $17-70 \%$ of major injuries ${ }^{10,11}$. Contusion was found in $2.3 \%$ of our patients. The reason for this difference may be that the patients in the literature have more $+1 \mathrm{mD}$ and vehicle traffic accident groups, and in our study group, $45.5 \%$ of the patients were in the $-1 \mathrm{mF}$ group. Ribs are less mineralized and more flexible in children than they are in adults, so during thoracic trauma, the ribs usually stretch and do not break ${ }^{12}$. In our study, rib fractures were seen in a total of 31 patients (3.2\%) and were found to be lower than some studies in the literature. It is thought that this case is due to the high number of our cases and the number of patients in the $-1 \mathrm{mF}$ group compared to the studies in the literature ${ }^{13}$.
$14(45.2 \%)$ of the patients who had rib fractures were in the $+1 \mathrm{mD}$ group. Only $1(5.5 \%)$ of 18 trauma patients with mortality had thoracic trauma (flail chest). In the series of thoracic trauma, the mortality rates detected in the hospital are as low as in our series ${ }^{14}$. This may be because many of the thoracic traumas result with death at the place of injury ${ }^{15}$.

Abdominal trauma accounts for $10-15 \%$ of children's traumas admitted to hospital ${ }^{16}$. In our study group, the rate of our patient with abdominal trauma was $3.3 \%$, which is not compatible with the literature, and it is thought that this is due to the high frequency of $-1 \mathrm{mF}$ group. Mortality was observed in two patients with abdominal trauma, and two patients had splenic injuries.

The rate of pediatric inpatients due to falling in pediatric trauma centers constitutes $25-34 \%$ of all child traumas and $6 \%$ of children who die from trauma.s ${ }^{17,18}$. Of the patients followed up in our series, $79.1 \%$ were trauma cases related to fall, and $11(1.4 \%)$ of these patients had mortality. When the relationship between trauma types and mortality was statistically analyzed, mortality was found to be higher in the $+1 \mathrm{mD}$ group, and mortality was not observed in the $-1 \mathrm{mF}$ group.

\section{CONCLUSION}

Trauma is a frequent occurrence in emergency departments in the pediatric age group, and trauma types are important for mortality. Therefore, when evaluating trauma patients, questioning trauma types is important in predicting the prognosis of the patient. Fast and urgent evaluation is valuable for survival. It is important to keep in mind that possible organ injuries are more common in certain types of trauma.

\section{REFERENCES}

1-DiGuiseppi C, Roberts IG. Individual-level injury prevention strategies in the clinical setting. Future Child 2000; 10:53-82.

2-Brook U, Boaz M. Children hospitalized for accidental injuries: Israeli experiences. Patient Education and Counseling 2003; 51: 177-82.

3-Fingerhut LA, Annest JL, Baker SP, et al. Injury mortality among children and teenagers in the United States. Inj Prev 1996; 2:93-4.

4 - Sieben RL, Leavitt JD, French JH. Falls as childhood accidents: an increasing urban risk. Pediatrics 1971; 47:886-92. 
5. Ceylan S, Acikel CH, Dundaroz R, et al. To determine the incidence and trauma characteristics of patients admitted to the emergency department of a training hospital. Turkey Clinics J Med Sci 2002; 22:156-61.

6. Wang MY, Kim KA, Griffith PM, et al. Injuries from falls in the pediatric population: an analysis of 729 cases. J Pediatr Surg 2001; 36:1528-34

7-Cooper A, Barlow B, DiScala C, et al. Mortality and truncal injury: The pediatric perspective. $\mathrm{J}$ Pediatr Surg 1994; 29:33-8.

8- Dalkılıç G, Öncel M., Acar H, et al. KEAH Emergency Surgery Clinic's four-year trauma

casting of diseases. Turkish Journal of Trauma and Emergency Surgery 1998; 4:17-22.

9- Al-Saigh A, Fazili FM, Allam AR. Chest trauma in children: A local experience. Ann Saudi Med. 1999; 19:106-9.

10- Cohen, MC. Pulmonary contusion: a review of the clinical entity. J Trauma 1997; 42: 973-9.

11- Grene R. Lung alterations in thoracic trauma. J Thorac Imaging 1987; 2: 1-11.
12-Meller JL, Little AG, Shermeta DW. Thoracic trauma in children. Pediatrics 1984; 74:813-819.

13-Çobanoğlu U., Melek M. Thorax Traumas Due to Fall in Childhood.

J Clin Anal Med 2011;2(3):11-5.

14- Peterson RJ, Tepas JJ III, Edwards FH, Niranjan K, Pieper P, Ceithaml EL. Pediatric and adult thoracic trauma: age-related impact on presentation and outcome. Ann Thorac Surg 1994; 58:14-8.

15-Melek M., Çobanoğlu U. Childhood Chest Trauma and Hemothorax. Van Medical Journal: 2009;16 (4):147-150.

16-Gaines BA. Intra-abdominal Solid Organ Injury in Children: Diagnosis and Treatment. The Journal of Trauma. 2009;67:S135-S139.

17- American Academy of Pediatrics. Committee on Injury and Poison Prevention. Falls from Heights: Windows, roofs, and balconies. Pediatrics 2001;107:1188-1191.

18- Committee on injury and poison prevention, American Academy of Pediatrics. Falls from heights: windows, roofs, and balconies. Pediatrics 2001;107:1188-1191. 